\title{
Aby Warburg: a astrologia como instrumento de orientação do homem no cosmos
}

Cássio da Silva Fernandes ${ }^{1}$

RESUMO: Discussão sobre o conjunto de textos do historiador da arte Aby Warburg (1866-1929) sobre o tema da astrologia do Renascimento, num arco temporal que vai de 1908 a 1929, considerando sua problemática histórico-cultural, bem como buscando compreender sua intenção de investigar o tema astrológico como instrumento de orientação do homem no cosmos.

PALAVRAS-CHAVE: Aby Warburg, astrologia, Renascimento, história da arte

\section{Aby Warburg: astrology as an instrument of orientation of man in the cosmos}

ABSTRACT: Discussion about the series of texts of the art historian Aby Warburg (18661929) on the theme of Renaissance astrology, in a temporal arc from 1908 to 1929, considering his historical-cultural problematic, as well as seeking to understand his intention of investigating the astrological theme as an instrument of human orientation in the cosmos.

KEYWORDS: Aby Warburg, astrology, Renaissance, art history

Os estudos de Aby Warburg (1866-1929) sobre astrologia ficaram conhecidos pela famosa conferência ${ }^{2}$ apresentada no X Congresso Internazionale di Storia dell'Arte di

\footnotetext{
${ }^{1}$ Doutor em História pela UNICAMP, é Professor Associado do Departamento de História da Arte da Universidade Federal de São Paulo (UNIFESP), responsável pela disciplina Arte e Cultura no Renascimento.

${ }^{2}$ WARBURG, A. Italienische Kunst und internatinale Astrologie im Palazzo Schifanoia zu Ferrara (1912). In: WARBURG, A. Gesammelte Schriften. Die Erneuerung der Heidnischen Antike. Band 2. Leipzig; Berlin: Teubner, 1932, pp. 459-481. Edição brasileira: WARBURG, A. A arte italiana e a astrologia
} 
Roma, em 1912, em que decifra os afrescos do Palácio Schifanoia a partir da história da tradição astrológica. ${ }^{3}$ (IMAGEM 1) Na conferência, intitulada "Arte italiana e astrologia internacional no Palácio Schifanoia de Ferrara", Warburg encontrava nos afrescos a confirmação de sua hipótese da transmissão ao Renascimento italiano de uma tradição iconográfica grega antiga, através da mediação indiana e árabe. Era esta uma forma de sobrevivência dos deuses pagãos que passava por um grande percurso migratório até tocar o território da Península Itálica, marcando a importância da tradição antiga para a formação da Europa no limiar do mundo moderno.

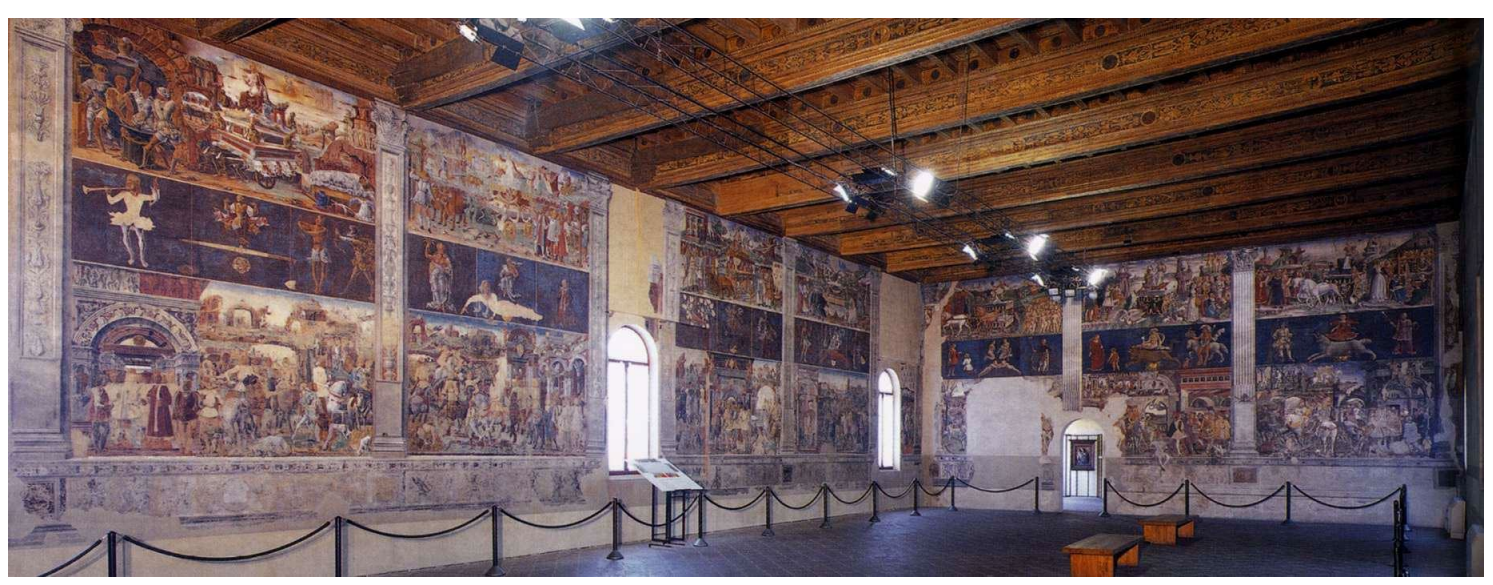

Francesco delCossae Ercolede' Roberti.

Salão dos Meses (1469-1470). Palácio Schifanoia, Ferrara.

Afrescos

Porém, no âmbito das pesquisas de Warburg, o tema da astrologia teve início antes de 1912 e ampliou-se para muito depois dessa data, adquirindo centralidade em sua obra até os últimos escritos, pouco antes de seu desaparecimento. $\mathrm{Na}$ pouco conhecida conferência autobiográfica (de título Vom Arsenal zum Laboratorium - De Arsenal a Laboratório $^{4}$ ), ministrada em 1927 por ocasião da reunião do conselho diretor da Kulturwissenschaftiche Bibliothek Warburg (Biblioteca Warburg para a Ciência da

internacional no Palazzo Schifanoia, em Ferrara (1912). In: WARBURG, A. A renovação da Antiguidade pagã. Rio de Janeiro: Editora Contraponto, 2013, pp. 453-505.

${ }^{3}$ Uma exposição foi realizada no Palácio Schifanoia, em 1998, sobre os estudos de Warburg a respeito dos afrescos astrológicos. Ver: FRATUCELLO, C.; KNORR, C. (a cura di). Il Cosmo incantato di Schifanoia. Aby Warburg e la storia delle immagini astrologiche. Guida alla mostra. Palazzo Schifanoia - Ferrara, 1998.

${ }^{4}$ WARBURG, A. De Arsenal a Laboratório. In: WARBURG, A. A Presença do Antigo. Escritos inéditos. Vol. 1. (Organização, tradução e notas: Cássio Fernandes). Campinas; São Paulo: Editora da UNICAMP; Editora da UNIFESP, 2018, pp. 37-52. 
Cultura), então sediada em Hamburgo, ele traça um breve esboço das etapas cruciais de seu percurso intelectual. A palestra marca o período final de sua vida, quando, recuperado do colapso psicológico, direciona os estudos ao mundo das formas simbólicas, como as tinha definido o seu amigo e colaborador dessa fase, Ernst Cassirer, autor do livro $\boldsymbol{A}$ Filosofia das Formas Simbólicas ${ }^{5}$. Na explanação de 1927, Warburg reporta-se a seus estudos astrológicos da seguinte maneira:

Desde quando, em 1907, li a obra Sphaera de meu inesquecível amigo [Franz] Boll, pude, de fato, incluir em minhas considerações o desenvolvimento do elemento cosmológico com sua riqueza de imagens. Então, junto a meu fiel amigo e assistente Fritz $\mathrm{Saxl}^{6}$, conseguimos criar uma ciência de orientação em forma de imagens, que nos autorizou a falar de uma nova história da arte científico-cultural, a qual não teria nem limites temporais, nem limites espaciais, ainda que cronologicamente concentrássemos nossa atenção no período de 2000 a.C. a 1650 d.C. Ao passo que geograficamente nos limitamos ao âmbito mediterrâneo, tendo que analisar um território que vai do Khorasan ${ }^{7}$ à Inglaterra, do Egito à Noruega. ${ }^{8}$

Segundo Warburg, ainda na palestra de 1927, este amplo estudo foi desenvolvido vislumbrando a "tarefa de considerar a obra de arte não apenas como espelho da vida histórica, mas também como instrumento de orientação no cosmos celeste" ${ }^{\text {. }}$.

De fato, em 1907 Warburg começava a estudar intensamente a história da mitografia e da astrologia, focalizando a descrição das divindades pagãs nos textos medievais e a continuidade do imaginário astrológico da Antiguidade nos tempos modernos, para se dedicar de modo sistemático aos estudos astrológicos a partir da leitura do livro de Franz Boll (1867-1924). O contato intelectual com Boll logo se transformaria também em profunda relação de amizade e numa colaboração de pesquisa que se estenderia por longo tempo, até a morte do filólogo, ocorrida em 1924.

\footnotetext{
${ }^{5}$ CASSIRER, E. Philosophie der symbolischen Formen. 3 Bände (Band. 1. Der Sprache. Band. 2. Das mythische Denken. Band. 3. Phänomenologie der Erkenntnis.), Berlin: Bruno Cassirer Verlag, 1923-1929. Edição Brasileira: CASSIRER, E. A Filosofia das Formas Simbólicas. 3 Volumes (A Linguagem; 2. O Pensamento Mítico; 3. Fenomenologia do Conhecimento). São Paulo: Martins Fontes, 2001-2011.

${ }^{6}$ A respeito dos estudos de Fritz Saxl sobre astrologia ver: SAXL, F. La fede negli astri. Dell'antichità al Rinascimento. A cura di Salvatori Settis. Torino: Editore Boringhieri, 1985.

${ }^{7}$ Região histórica compreendida principalmente no atual Irã. Foi anteriormente conhecido como Pártia; mais tarde, durante a era Sassânida, passou a ser chamada Khorasan.

${ }^{8}$ WARBURG, A. De Arsenal a Laboratório. In: WARBURG, A. A Presença do Antigo. Escritos inéditos. Vol. 1. (Organização, tradução e notas: Cássio Fernandes). Campinas; São Paulo: Editora da UNICAMP; Editora da UNIFESP, 2018, p. 48.

${ }^{9}$ Idem.
} 
Filólogo clássico, professor na Universidade de Heidelberg, especialista em história da astrologia, Franz Boll havia publicado, em 1903, Sphaera. Neue griechische Texte und untersuchungen zur geschichte der Sternbilder (Sphaera. Novos textos gregos e estudos para a história das constelações) ${ }^{10}$. Nesse livro, Boll conseguira restituir um dos mais influentes tratados sobre o céu da Antiguidade Clássica, a Sphaera Barbarica, do babilônico Teucro (séc. I a.C.). Partindo, então, do tratado de Teucro, Boll empreende uma reconstrução detalhada da migração da astrologia e da astronomia grega através de suas transmissões no Oriente e na Idade Média Latina. O texto de Teucro mostrava já, por sua vez, a contaminação e o enriquecimento da sphaera clássica com novos asterismos orientais, ou seja, o catálogo das estrelas fixas de Arato (séc. III a.C.) ${ }^{11}$. Na época helenística, este céu de poucas constelações foi preenchido com novas figuras provenientes da tradição egípcia, aramaica e babilônica. Este catálogo de constelações, mescla de elementos gregos e orientais, teve grande fortuna e, no curso do tempo, foi enriquecido com ornamentos astrológicos indianos e persas. Portanto, o tema do livro de Franz Boll é a história da compilação de Teucro, e de suas migrações na Antiguidade e na Idade Média, entre diversas culturas no Oriente e no Ocidente.

Entretanto, o impulso decisivo para a pesquisa astrológica de Warburg ocorreu com a publicação, em apêndice ao livro de Boll, de uma tradução realizada por Karl Dyroff. Orientalista de Munique, Dyroff tinha publicado, na versão árabe, ao lado de uma minuciosa revisão da tradução latina e com uma tradução para o alemão, o fundamental livro para os astrólogos da Idade Média, a Introductorium magnum in astronomiam ${ }^{12}$, conhecida também como Grande Introdução, do astrólogo árabe Abu Ma'shar, que viveu em Bagdá e morreu em 886. Este tratado é uma versão da Sphaera Barbarica de Teucro, surgida desta vez do cruzamento das vias de comunicação entre Egito e Índia, contendo a descrição da divisão do zodíaco em 36 decanos. Abu Ma'shar estabelece esta descrição dos decanos segundo a tradição árabe, greco-ptolomaica e indiana.

A importância da obra de Abu Ma'shar para o conhecimento astrológico medieval se confirmaria, tempos depois, no teor dos textos de Fritz Saxl (assistente de Warburg na

\footnotetext{
${ }^{10}$ BOLL, F. Sphaera. Neue griechische Texte und Untersuchungen zur Geschichte der Sternbilder. Leipzig: Teubner, 1903.

${ }^{11}$ Utilizamos aqui a edição em espanhol: ARATO. Fenómenos. Madrid: Editorial Gredos, 1993.

${ }^{12}$ MA'SHAR, A. Introductorium in astronomiam Albumasaris Abalachi octo continens libros partiales. Venezia: Jacob Pentius Leucensis, 1506.
} 
Biblioteca Warburg para a Ciência da Cultura, em Hamburgo) sobre o tema, editados postumamente no livro La Fede negli astri ${ }^{13}$, mas também pela centralidade ganha pelo erudito árabe no livro de Eugenio Garin, O Zodíaco da Vida ${ }^{14}$. Exatamente o livro em que Garin compreende a astrologia como uma potência ativa na formação da "visão de mundo" (Weltanschauung) no Renascimento. Pelas palavras de Garin, que reproduzimos em seguida, fica claro que a astrologia não era apenas uma técnica de previsão, mas uma concepção geral da realidade e da história:

Astrologia e religião; astrologia e política, mas também astrologia e medicina: uma filosofia da história, uma concepção das realidades, um naturalismo fatalista, um culto astral - a astrologia era tudo isso e ainda mais. ${ }^{15}$

De todo modo, o livro de Franz Boll despertara em Warburg o interesse pelo estudo dos textos astrológicos indianos, fundamentais para o desenvolvimento de toda sua pesquisa astrológica. Em primeiro lugar, porque o método de estudo de Boll ia ao encontro de seu interesse de perfazer os caminhos migratórios que confluíram para a formação do imaginário astrológico na cultura e na arte renascentista. Os problemas históricos trazidos pelos estudos de Franz Boll permitiram ainda a Warburg seguir hipóteses de trabalho que cumpriam uma ampliação nos limites temáticos, geográficos e metodológicos de suas pesquisas, ampliando a concepção de Antigo, além da noção de Renascimento, que dela descendia. Tudo isso confluía ainda para a abordagem histórica da temática da astrologia buscada por Warburg, onde a operação histórico-cultural conferia à imagem um papel essencial, considerada como espelho côncavo em que refletem os vários produtos da cultura: a linguagem, o conhecimento científico, o mito, a religião.

O Antigo, para Warburg, não se limitava à esfera determinada pelo Mundo Clássico, mas circunscrevia um universo muito mais amplo, helenístico, como presente em sua afirmação na conferência de 1927: incluía o Mediterrâneo Oriental e a Índia, desde o Khorasan. O Antigo, para Warburg, incluía a Grécia Clássica, mas se expandia, a partir dela, em direção à geografia da Grécia Helenística (IMAGEM 2), e isso põe problemas que são primordiais, determinantes, em sua compreensão desse conceito. Assim, o

\footnotetext{
${ }^{13}$ SAXL, F. La Fede negli astri. Dall'antichità al Rinascimento. Torino: Bollati Boringhieri 1985.

${ }^{14}$ GARIN, E. O Zodíaco da Vida. A polêmica sobre a astrologia do século XIV ao século XVI. Lisboa: Editorial Estampa, 1987.

${ }^{15}$ Idem, p. 43.
} 
equilíbrio sob o qual fora concebido o conceito de clássico ganhava uma interpretação renovada. Trata-se da correção à doutrina de Lessing, ou mais exatamente à ideia de Winckelamnn a respeito da serenidade olímpica da Antiguidade, que, segundo o próprio Warburg, na citada conferência autobiográfica de 1927, desenvolveu-se em sua mente logo após o início de seu percurso acadêmico, quando estudava na Universidade de Bonn, e teria se baseado num fundamento histórico-cultural. Ele revela também que esta ideia era, ainda no momento da explanação de 1927, uma perspectiva sobre a qual se colocava; portanto, não totalmente concluída. ${ }^{16}$ Seus estudos sobre a astrologia estão intimamente ligados a esse amplo problema histórico.

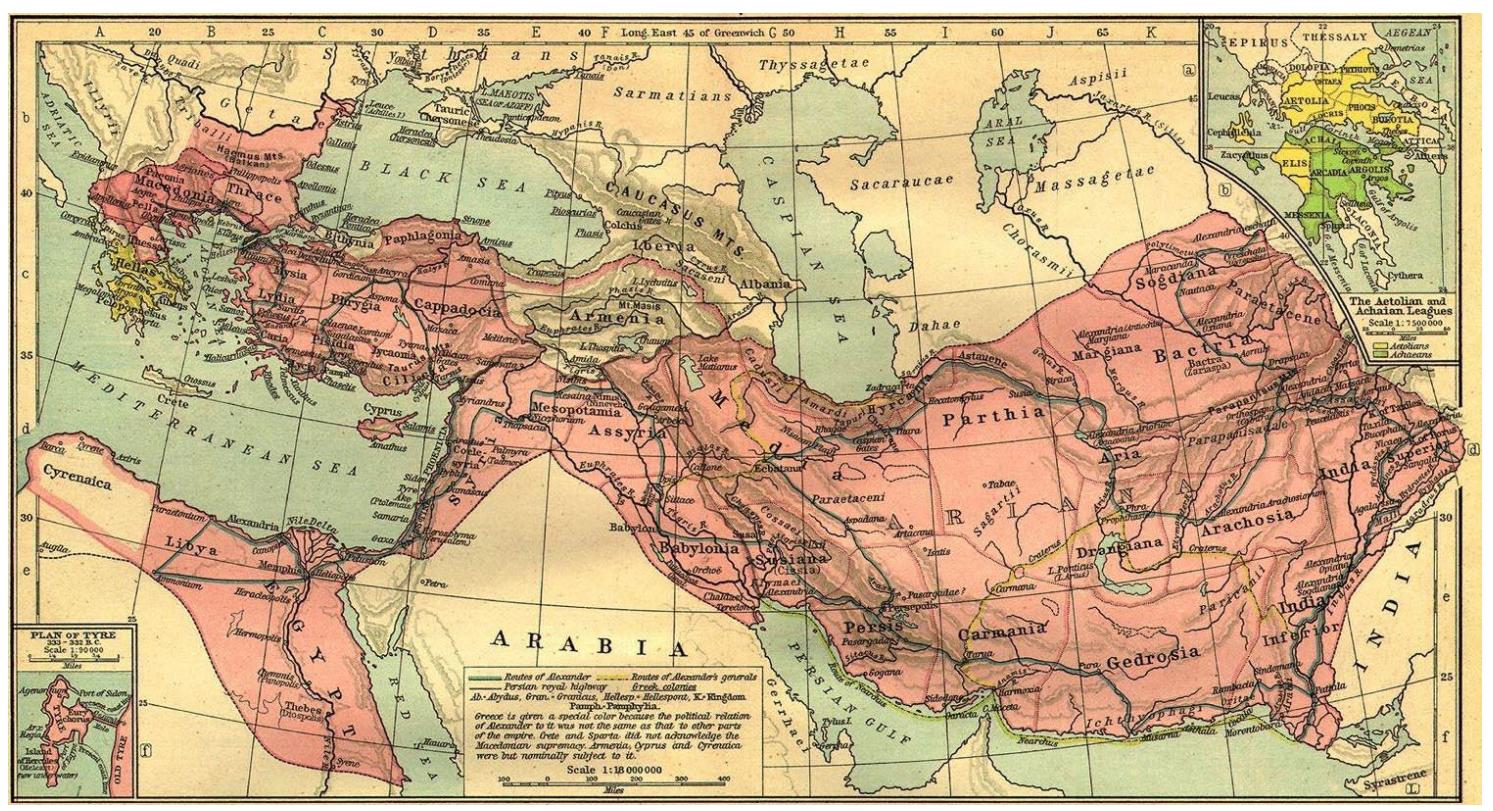

Grécia Helenística

(Ilustração: Universidade do Texas. HistoricalAtlas byWilliam Shepherd)

Ao tratar o tema da astrologia, Warburg buscou compreender o quanto o classicismo grego estava perpassado por elementos orientais, oriundos do Egito, da Pérsia, da Mesopotâmia, portanto, sua noção de Antigo tinha uma forte dose do primitivismo a minar o equilíbrio olímpico das divindades gregas. Consequentemente, a absorção pelo Ocidente latino medieval do universo das interpretações árabes e indianas

${ }^{16}$ Ver: WARBURG, A. De Arsenal a Laboratório, op. cit., p. 39. 
do mundo grego antigo permite a construção de um caminho migratório muito amplo a conectar o Renascimento italiano à Antiguidade.

Além disso, o exame paralelo dos textos e das imagens astrológicas, num arco temporal que culmina com o processo de constituição do mundo moderno, permite ao estudioso de Hamburgo sondar as imbricações de duas linhas de pensamento coexistentes: de um lado, as superstições e os fatalismos astrais no Ocidente latino na Idade Média tardia e no início do Renascimento; de outro, a reestruturação das ferramentas mentais que possibilitaram o domínio e organização do cosmos pela ciência matemática moderna. Warburg percebe, a partir de sua pesquisa sobre astrologia, que o homem seguiu nesse processo oscilando entre duas causas originárias: uma, que se apresenta nas imagens mitológicas; outra, que é numericamente calculável. Nesse sentido, para ele, as constelações assumem um caráter ambivalente, polar, que de um lado exigem uma veneração cultual na prática mágica, e, de outro, têm o valor de uma determinação da extensão separada e objetiva em relação aos corpos luzentes no espaço do universo, na abóbada celeste. Essa dicotomia, que marca a interpretação de Warburg das representações astrológicas no limiar da Época Moderna, está em inteiro acordo com sua interpretação da face bipolar do Renascimento.

Vejamos brevemente como se dá o percurso dos estudos astrológicos na obra de Warburg.

Os primeiros textos de Warburg sobre o tema da astrologia remontam a 1908 e se inserem em sua obra como uma continuidade em relação aos estudos de 1902, sobre a circulação artística entre Florença e Flandres, concluídos em 1907, com o belo ensaio intitulado A última vontade de Francesco Sassetti ${ }^{17}$, onde analisa o escrito testamentário do mercador florentino. Em 1902, Warburg tinha compreendido o papel da burguesia florentina na formação de um gosto artístico que mirava a arte flamenga por sua capacidade de ilusão realística e pela facilidade de circulação de seus produtos em quadros de pequenas dimensões e em tapeçarias. ${ }^{18}$ Ele tinha observado que as primeiras

\footnotetext{
17 WARBURG, A. Francesco Sassettis letzwillige Verfügung (1907). In: WARBURG, A. Gesammelte Schriften. Die Erneuerung der Heidnischen Antike. Band 1, op. cit., pp. 127-157. Edição brasileira: WARBURG, Aby. A última vontade de Francesco Sassetti (1907). In: WARBURG, A. A renovação da Antiguidade pagã , op. cit., pp. 169-217.

${ }^{18}$ WARBURG, A. Flandrische Kunst und florentinischen Frürenaissance (1902). In: WARBURG, A. Gesammelte Schriften. Die Erneuerung der Heidnischen Antike. Band 1, op. cit., pp.185-206. Edição
} 
coleções privadas em Florença eram uma reunião de tapeçarias produzidas em Flandres e de obras pictóricas trazidas de lá. Saltava a seus olhos o fato de que a arte flamenga levada para Florença, na metade do século XV, era, em muitos casos, o resultado do contato entre toscanos e flamengos. Isso por dois motivos: primeiro, porque era um fato a execução de tapeçaria flamenga com base em desenhos italianos; segundo, porque chegavam a Florença, concomitantemente, quadros executados por artistas flamengos a partir de encomenda realizadas pela alta burguesia florentina. Assim, pensava ele, o estilo realístico flamengo passara a influenciar a arte florentina, atuando na formação, em Florença, de um estilo ao qual chamou alla franzese.

Em 1908, ao adentrar ao universo da astrologia, ele se concentra na relação entre arte italiana e arte nórdica, mas agora observando o problema a partir de um caminho inverso. Agora seu foco é o início do século XVI, período em que a arte da tapeçaria tinha perdido lugar para o surgimento da imprensa moderna, e, consequentemente, para a difusão da gravura. Seu foco geográfico transmuta de Flandres para o mundo renano, portanto, para o contexto da profusão da imprensa. É o mundo dos impressores renanos, de Erasmo de Rottendan, de Lutero, de Dürer e de uma infinidade de gravuristas. A gravura tinha tomado o lugar da tapeçaria na relação artística entre Sul e Norte. Seu enfoque no Sul ultrapassa os limites de Florença, para atingir a Itália de modo mais geral. Com relação ao Norte, sua atenção desloca-se, então, de Flandres para o sul da Germânia. Esse é o tema de seus textos de 1908: "Sobre as imagens das deidades planetárias no calendário baixo-alemão de $1519 " 19$ e "O mundo antigo dos deuses e o início do Renascimento no Norte e no Sul" ${ }^{20}$. Trata-se de textos curtos, anotações breves, a partir das quais Warburg observa uma nova época de intercâmbios de cultura artística entre o Norte e o Sul. É importante notar que aqui o estudioso busca compreender os meandros de um novo modelo de transmissão artística, que atua na formação de um novo estilo na

brasileira: WARBURG, A. Arte flamenga e início do Renascimento florentino (1902). In: WARBURG, A. A renovação da Antiguidade pagã, op. cit., pp. 245-275.

19 WARBURG, A. Über Planetengötterbilder im niederdeutchen Kalendar Von 1519 (1908). In: WARBURG, A. Gesammelte Schriften. Die Erneuerung der Heidnischen Antike. Band 2, op. cit., pp. 483-486. Edição brasileira: WARBURG, A. Sobre as imagens das deidades planetárias no calendário baixoalemão de 1519 (1908). In: WARBURG, A. renovação da Antiguidade pagãa, op. cit., pp. 507-513.

${ }^{20}$ WARBURG, A. Die Antike Götterwelt und die Frührenaissance im Süden und im Norden. (1908). In: WARBURG, A. Gesammelte Schriften. Die Erneuerung der Heidnischen Antike. Band 2, op. cit., pp. 451-454. Edição brasileira: WARBURG, Aby. O mundo antigo dos deuses e o início do Renascimento no Norte e no Sul (1908). In: WARBURG, A. A renovação da Antiguidade pagã, op. cit., pp. 447-448. 
arte. Agora é a Itália que oferece ao mundo nórdico o seu legado cultural e artístico. É o grande legado italiano, assentado na noção de Antigo, que atinge o mundo nórdico por meio da passagem cumprida pela execução em gravura de desenhos italianos. Desenhos italianos concebidos num momento em que o legado antigo toca efetivamente a arte italiana: é a época das descobertas arqueológicas principais, como o grupo escultórico "Laocoonte", é a fase da atuação de Michelangelo em Roma, dos projetos arqueológicos e artísticos de Rafael na Cidade Eterna. Em seguida virá a obra dos principais alunos de Rafael e Michelangelo.

Nesse contexto, a gravura assume um papel político importante ao norte dos Alpes. Transforma-se em veículo de propaganda política pró e contra a Reforma. Mas também, nesse momento, a gravura nórdica é produzida num ambiente intelectual em que transitam Dürer, Steffen Arndes e vários outros artífices de primeiro nível. ${ }^{21}$ Nesse trânsito, aporta ao Norte o estilo ideal antiquizante (segundo o denomina Warburg) por meio da execução germânica de desenhos itálicos. O estilo do Alto Renascimento atinge em cheio o Norte, e leva consigo o paganismo na forma e no conteúdo das obras. A astrologia é um dos temas preferidos desse produto artístico em difusão, e é vetor, portanto, da passagem do estilo alla franzese (do início do Renascimento) para o estilo all'antica (do Alto Renascimento). Assim, o Antigo aporta ao mundo nórdico, provindo da Itália, e carrega o que Warburg denomina "formulações de pathos" (Pathosformeln), ou seja, aquela tensão psicológica expressa nos movimentos dos corpos e nos gestos, revelando que no legado Antigo não se apresenta apenas o controle racional, a gestualidade apolínea, mas também uma comoção de alma, uma reação patológica.

Em seguida, em 30 de dezembro de 1909, Warburg estabelece o primeiro contato com Franz Boll, através de uma carta. A partir daí, intensifica-se a comunicação epistolar entre os dois, e, em outubro de 1910, encontram-se pela primeira vez, em Hamburgo. O plano de visitarem juntos o Palácio Schifanoia de Ferrara, entretanto, jamais se concretizaria. De todo modo, a partir do contato com Boll, Warburg amplia sobremaneira a geografia de sua pesquisa sobre os intercâmbios culturais e artísticos entre Norte e Sul,

\footnotetext{
${ }^{21}$ Warburg tratará este tema também posteriormente, como fica atestado em seu estudo publicado em 1920: WARBURG, A. Heidnisch-antike Weissagung in Wort und Bild zu Luthers Zeiten (1930). In: WARBURG, A. Gesammelte Schriften. Die Erneuerung der Heidnischen Antike. Band 2, op. cit., pp.487-558. Edição brasileira: WARBURG, Aby. A antiga profecia pagã em palavras e imagens nos tempos de Lutero (1920). In: WARBURG, A. A renovação da Antiguidade pagã, op. cit., pp. 515-621.
} 
abarcando agora um trajeto que vai da Grécia helenística até o Norte europeu no Renascimento.

Em 1912, partindo de uma palestra apresentada anteriormente (em 1911), Aby Warburg ministra, no $X$ Congresso Internazionale di Storia dell'Arte di Roma, a já mencionada conferência em que decifra os afrescos do Palácio Schifanoia (IMAGEM 1) a partir da história da tradição astrológica. ${ }^{22}$ A conferência, intitulada "Arte italiana e astrologia internacional no Palazzo Schifanoia de Ferrara", representaria também o momento de apresentação para um público internacional de sua operação históricocultural, onde a abordagem iconológica figurava em gênese.

E a conferência de Warburg sobre os afrescos astrológicos do Palácio Schifanoia, que cita de início o livro Sphaera, de Franz Boll, segue o caminho migratório do tratado de Teucro até sua recepção na Corte de Ferrara, no círculo do Duque Borso d'Este. Porém, para além do estudo de Franz Boll, Warburg alinhava o último fio da intrincada tessitura dessa transmissão histórica, esclarecendo quem poderia ter sido o erudito inspirador do programa iconográfico dos afrescos. Para isso, o estudioso de Hamburgo utiliza-se do recurso tomado das lições aprendidas com os textos de Jacob Burckhardt (a quem chamava "nosso mestre") sobre a arte italiana do Renascimento, escritos do final do século XIX. ${ }^{23}$ Ou seja, Warburg centraliza sua indagação no processo criativo da obra em questão, focando sua indagação na relação entre comitente, artista e conselheiro erudito. Quem teria sido o literato idealizador do plano iconográfico dos afrescos astrológicos do Palácio Schifanoia? E chega à figura de Pelegrino Prisciani, historiógrafo da Corte dos Este em Ferrara e autor da Historiae Ferrariae, a qual, na quarta parte do capítulo XLVIII, continha um ponto de vista sobre a humanidade e o firmamento a partir de

\footnotetext{
${ }^{22}$ WARBURG, A. Italienische Kunst und internatinale Astrologie im Palazzo Schifanoia zu Ferrara (1912). In: WARBURG, A. Gesammelte Schriften. Die Erneuerung der Heidnischen Antike. Band 2, op. cit., pp. 459-481. Edição brasileira: WARBURG, A. A arte italiana e a astrologia internacional no Palazzo Schifanoia, em Ferrara (1912). In: WARBURG, A. A renovação da Antiguidade pagã. op. cit., pp. 453505.

${ }^{23}$ Esses escritos de Jacob Burckhardt trataram a pintura italiana do Renascimento a partir de três ensaios publicados em origem postumamente, em 1898, sobre "O retrato na pintura", "O retábulo de altar" e "Os colecionadores". Edição recente desse livro: BURCKHARDT, J. Beiträge zur Kunstgeschichte Von Italien: das Altarbild; das Porträt in der Malerei; die Sammler. In: Jacob Burckhardt Werke. Band 6. München; Basel: C. H. Beck; Schwabe \& Co., 2000.

No Brasil, foi editado o escrito sobre o retrato na pintura: BURCKHARDT, J. O Retrato na Pintura Italiana do Renascimento. (Organização, tradução e notas: Cássio Fernandes). Campinas; São Paulo: Editora da UNICAMP; Editora FAP-UNIFESP, 2012.
} 
investigações sobre a Cosmographia segundo a tradição greco-ptolomaica. Nessa parte, Prisciani indica expressamente os seus primeiros estudos astrológicos e cita alguns exemplos de práticas mágicas tomadas de Pietro d'Abano, tradutor para o latim da "bíblia" da astrologia medieval, exatamente a Grande Introdução de Abu Ma’shar. Além disso, o conhecimento mágico-astrológico de Pellegrino Prisciani ficara atestado, para conhecimento de Warburg, numa carta escrita pelo erudito à Duquesa Leonora de Ferrara, em 26 de outubro de 1487. Eram provas indiciárias de que teria sido Prisiciani o erudito inspirador do ciclo de afrescos astrológicos do Salão dos Meses do Schifanoia.

Assim, ocorria em Ferrara, através de uma migração milenar, a restauração dos deuses olímpicos pela via da prática astrológica medieval, oriental-latina, representada na faixa do meio dos afrescos. Cumpria-se uma infiltração demonológica oriental na recepção ferraresa do céu das estrelas fixas gregas, através da qual as divindades olímpicas renasciam, no ambiente da corte de Borso d'Este, sob as vestes de demônios astrais.

Mas o contato intelectual entre Aby Warburg e Franz Boll seria intensificado a partir de então. Em 1913, a convite de Warburg, Boll vai a Hamburgo e ambos ministram juntos um curso de verão sobre o tema da astrologia. Como conclusão do curso, Warburg profere duas conferências, nos dias 5 e 6 de agosto de 1913, que tiveram o título: $A s$ imagens das estrelas fixas da Sphaera Barbarica na migração do Leste para o Oeste (Die Fixsternhimmelsbilder der "Sphaera Barbarica" auf der Wanderung von Ost nach West) e As imagens dos planetas em sua migração do Sul para o Norte e em seu reemergir na Itália (Die Planetenbilder auf der Wanderung von Süd nach Nord und ihre Rückehr nach Italien) ${ }^{24}$. Essas conferências são ainda hoje pouco conhecidas. Na parte inicial da primeira conferência, Warburg apresenta o problema que irá tratar. Ele afirma:

Para a história do desenvolvimento da arte europeia é importante reconstruir cientificamente a específica polaridade psíquica do homem comum medieval, já que o Renascimento italiano, cujo caráter tinha-se realizado na restauração da beleza antiga, deveria liberar-se das figuras dos antigos deuses olímpicos, exatamente daquela esfera que oscilava no todo semi-escuro entre ciência e magia. O propósito de minhas duas conferências é mostrar que esta libertação representou um ato de consciente transformação. A Itália, verdadeira herdeira e co-sanguínea

${ }^{24}$ WARBURG, A. Die Fixternhimmelsbilder der Sphaera Barbarica auf der Wanderung von Ost nach West (1913). Die Planetenbilder auf der Wanderung von Süd nach Nord und ihre Rückehr nach Italien (1913). In: WARBURG, A. Werke. Berlim: Suhrkamp Verlag, 2018, pp. 326-348; pp. 349-372. 
da cultura antiga, tomou conscientemente como espólio, seguindo o verdadeiro modelo da literatura e das artes antigas renascidas, as figuras dos deuses pagãos naquele disfarce maravilhoso e um tanto estratificado sob o qual eles tinham conduzido a sua existência, banida da Igreja, e revivificada, na Idade Média, no curso de sua migração de leste a oeste e de sul a norte. ${ }^{25}$

E, de modo mais preciso, indica como seguirá o tema:

Na primeira conferência, buscarei traçar uma linha longitudinal de tipo geográfico e cronológico, seguindo as etapas principais da migração das estrelas fixas, isto é, da chamada Sphaera Barbarica, de Alexandria a Bagdá e, via Toledo, a Padova, Ferrara e Perugia. Na segunda conferência, tentarei seguir um corte transversal histórico e iconológico que focalizará os movimentos do motivo figurativo através das imagens de Vênus, Mercúrio e Saturno. O propósito de minhas conferências é mostrar, infelizmente de modo muito sintético, como nas representações do antigo mundo das imagens astrais desenvolve o duplo movimento ondulatório da cultura helenística de leste a oeste e de sul a norte. ${ }^{26}$

Warburg, então, segue na linha interpretativa que tinha marcado a conferência do ano anterior, sobre o Palácio Schifanoia, dirigindo, no entanto, o foco da transmissão da Sphaera Barbarica de Teucro para outros contextos e outras imagens. Partindo de estudos iconológicos, move-se em direção à história das religiões e das crenças, e, assim, através da constituição de uma gramática visual, deságua numa pesquisa de viés antropológico. E observa que o nascimento e a persistência da astrologia dizem respeito a uma necessidade psíquica profunda, a qual faz permanecer vivo o elemento biomórfico. Isso se dá devido à oscilação psíquica "entre um movimento religioso e outro científico". Como afirma, trata-se de "um método com base no qual se pode acreditar e elaborar uma relação humana e pessoal com o cosmos" ${ }^{27}$.

Assim, nesse amplo conjunto de escritos sobre astrologia figura o texto de 1920, surgido como reelaboração da palestra de 1917: A antiga profecia pagã em palavra e imagem nos tempos de Lutero (assim na edição brasileira). ${ }^{28}$ Aqui, seu interesse é

\footnotetext{
${ }^{25}$ WARBURG, A. Die Fixternhimmelsbilder der Sphaera Barbarica auf der Wanderung von Ost nach West (1913). In: WARBURG, A. Werke. Berlim: Suhrkamp Verlag, 2018, p. 328.

${ }^{26}$ Idem, p. 329.

${ }^{27}$ Idem, p. 328.

${ }^{28}$ Em 12 de novembro de 1917, Warburg ministra no Verein für hamburgische Geschichte uma conferência de título Reformatorische Weissagung im Wart und Bild zu Luthers Zeiten (Profecia reformatória em palavra e imagem na época de Lutero), que depois, ampliada, foi publicada com o título Heidnisch-antike Weissagung in Wort und Bild zu Luthers Zeiten (Antiga profecia pagã em palavra e imagem na época de Lutero) nos Sitzungsberichte der Heidelberger Akademie der Wissenschaften. Philologisch-historische Klasse, XXVI (1919), Heidelberg, 1920.

Esta última versão do texto foi publicada na citada edição canônica dos escritos do autor, em 1932: WARBURG, A. Heidnisch-antike Weissagung in Wort und Bild zu Luthers Zeiten. In: WARBURG, A.
} 
compreender o modo como as imagens astrológicas produzidas pelas prensas da primeira geração dos estampadores modernos germânicos assumem uma função político-religiosa, pondo no centro a figura de Martinho Lutero, no mesmo momento em que promovem um renascimento de imagens Antigas no contexto das disputas reformistas.

Para Warburg, o efeito dos planetas na percepção da história durante a Idade Média persistia na época da Reforma e, portanto, era forte a convicção do papel das conjunções nas profecias astrológicas e, em consequência, estas assumiam grande poder na doutrina que unia a verdade mítica trazida pela prática astrológica com a concepção dos desígnios da história. Portanto, era preciso conhecer o papel dos planetas sobre a realidade terrena para encontrar um espaço de atuação (quando necessário) nos destinos da história. É sobre esta base ideal que a figura histórica de Lutero é submetida a uma disputa política a partir da discussão, através de textos e de imagens, sobre as conjunções astrais.

No entanto, anos depois, em 25 de abril de 1925, Aby Warburg ministra em sua biblioteca, em Hamburgo, uma conferência em homenagem a Franz Boll, à qual deu o título: Die Einwirkung der Sphaera barbarica auf die kosmischen Orientierungsversuche des Abendlandes. Franz Boll zum Gedächtnis (A influência da Sphaera Barbarica sobre as tentativas de orientação no Cosmos no Ocidente. Em memória de Franz Boll) ${ }^{29}$. A palestra, inédita até poucos anos atrás, uma homenagem a Boll no ano seguinte à sua morte, cumpre a dupla tarefa de apresentar uma síntese do resultado de suas pesquisas astrológicas e de demonstrar solenemente o quanto seus próprios estudos deveram ao trabalho do filólogo e amigo.

$\mathrm{Na}$ conferência, Warburg trabalha com um problema histórico-cultural que ele próprio define como:

a possibilidade de compreender a restauração da Antiguidade como uma tentativa (talvez não sedutora do ponto de vista estético, mas que nos ata ainda mais

Die Erneuerung der heidnischen Antike. Band II. Op. cit., pp. 487-558. Edição brasileira: WARBURG, Aby. A antiga profecia pagã em palavras e imagens nos tempos de Lutero. In: WARBURG, A. A renovação da Antiguidade pagã. Op. cit., pp. 515-621.

${ }^{29}$ Edição brasileira: WARBURG, A. A influência da Sphaera Barbarica sobre as tentativas de orientação no cosmos no Ocidente. Em memória de Franz Boll. In: WARBURG, A. A Presença do Antigo. Escritos inéditos. Vol. 1. Op. cit. pp. 141-196.

Outra edição brasileira em: WARBURG, A. A influência da Sphaera Barbarica sobre as tentativas de orientação cósmica no Ocidente. In: WARBURG, A. Historias de fantasmas para gente grande. Escritos, esboços e conferencias. Organizado por Leopoldo Waizbort. São Paulo, Companhia das Letras, 2015, pp. 289-347. 
profundamente ao humano) de libertar a personalidade moderna do encanto da prática mágica helenística. ${ }^{30}$

Para ele, a astrologia é um testemunho essencial para a História da Cultura no limiar do Mundo Moderno, visto que no conhecimento do céu cruzamos com a mais ampla questão da orientação espiritual diante do universo. Assim, pretende demonstrar, em palavra e em imagem, que o homem, na posição de observador, luta por um espaço de pensamento. Desenvolve a ideia de que a matemática grega, cujas formas originárias retornaram no curso do Renascimento, ofereceu ao homem europeu a arma para combater os demônios astrais provenientes da Grécia asiática.

A Grécia de Warburg, afirmamos anteriormente, é entendida como um território de fronteira, um campo de encontros culturais marcado por tensões. (IMAGEM 2) A astrologia é, ela própria, a expansão significativa desse campo de forças. Ela chega ao homem do Renascimento por meio de uma transmissão que carrega, por sua vez, elementos oriundos do mundo tardo-antigo indiano, medieval árabe e espanhol. Assim, o princípio matemático numérico, que havia caracterizado a astronomia grega em sua origem, é transformado pelo contato com a magia tardo-antiga. A magia se expressa como uma cosmologia aplicada. Uma aplicação que, no fim, desemboca numa prática manipuladora do princípio da igualdade entre sujeito e objeto. De modo que o homem, como microcosmo, é entendido pelo astrônomo em relação direta com o mundo dos astros, numa época em que não tinha sido ainda inventado o microscópio. O "Homem Zodiacal" medieval é exemplo desse processo. (IMAGEM 3) Produto dessa compreensão relacional entre homem e cosmos, surge o "Homem Zodiacal", imagem que concebe, através do fenômeno conhecido como "melothesia", o modo como as configurações astrais interferem em cada órgão do corpo humano. Trata-se de uma compreensão de mundo expressa pela filosofia e pela medicina, que está na base da astrologia tardomedieval. Essas imagens se proliferam no Ocidente latino.

\footnotetext{
${ }^{30}$ WARBURG, A. A influência da Sphaera Barbarica sobre as tentativas de orientação no cosmos no Ocidente. Em memória de Franz Boll. In: WARBURG, A. A Presença do Antigo. Escritos inéditos. Vol. 1. Op. cit., p. 144.
} 


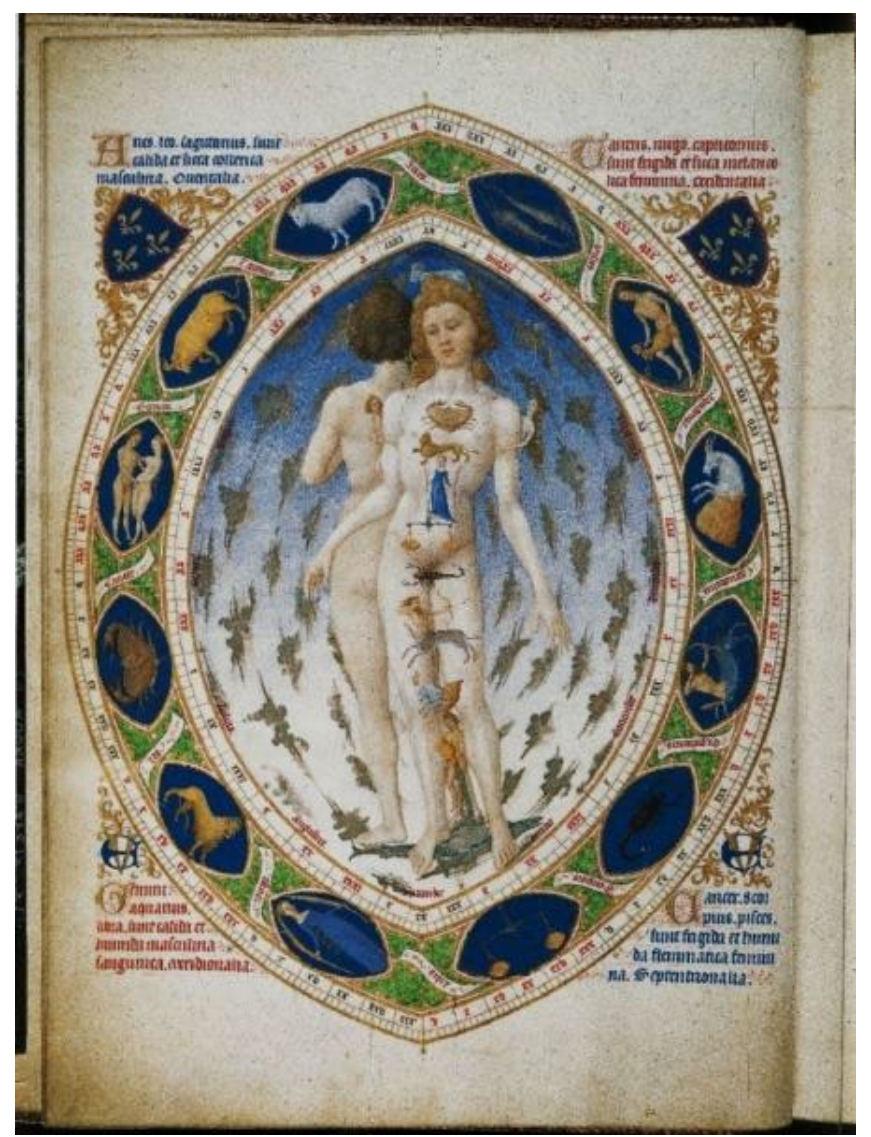

Homem Zodiacal.

Livre d'Heuresdo Duque de Berry. MuséeCondé: Chantilly, 1420 c.

Iluminura, $29 \mathrm{~cm} \mathrm{X} 21 \mathrm{~cm}$

Mas, Warburg pretende entender, na conferência de 1925, o processo que levou à compreensão astrológica da "terribilità" do "monstrum", da antropomorfização do cosmos (regida por sacrifícios, conhecimento tomado a partir dos "fígados da advinhação" - a hepatologia) (IMAGEM 4) em direção à contemplação, na esfera ideal, da mediação pagã erudita. Daí o mote, que ele toma de Franz Boll: "Per monstra ad sphaeram!" (Dos monstros à esfera!). (IMAGEM 5) Ou seja, da fortuna da Sphaera Barbarica de Teucro, sobrevivida no papel desempenhado na astrologia medieval e do início do Renascimento pela Grande Introdução de Abu Ma'shar no Ocidente latino, até a descoberta da esfera pelo astrônomo renascentista. A conquista da esfera representava a conquista do Antigo pela astrologia/astronomia do Renascimento. Este é o percurso do Renascimento entendido como época histórico-cultural, portanto, como período de transição entre a Idade Média e o Mundo Moderno. 


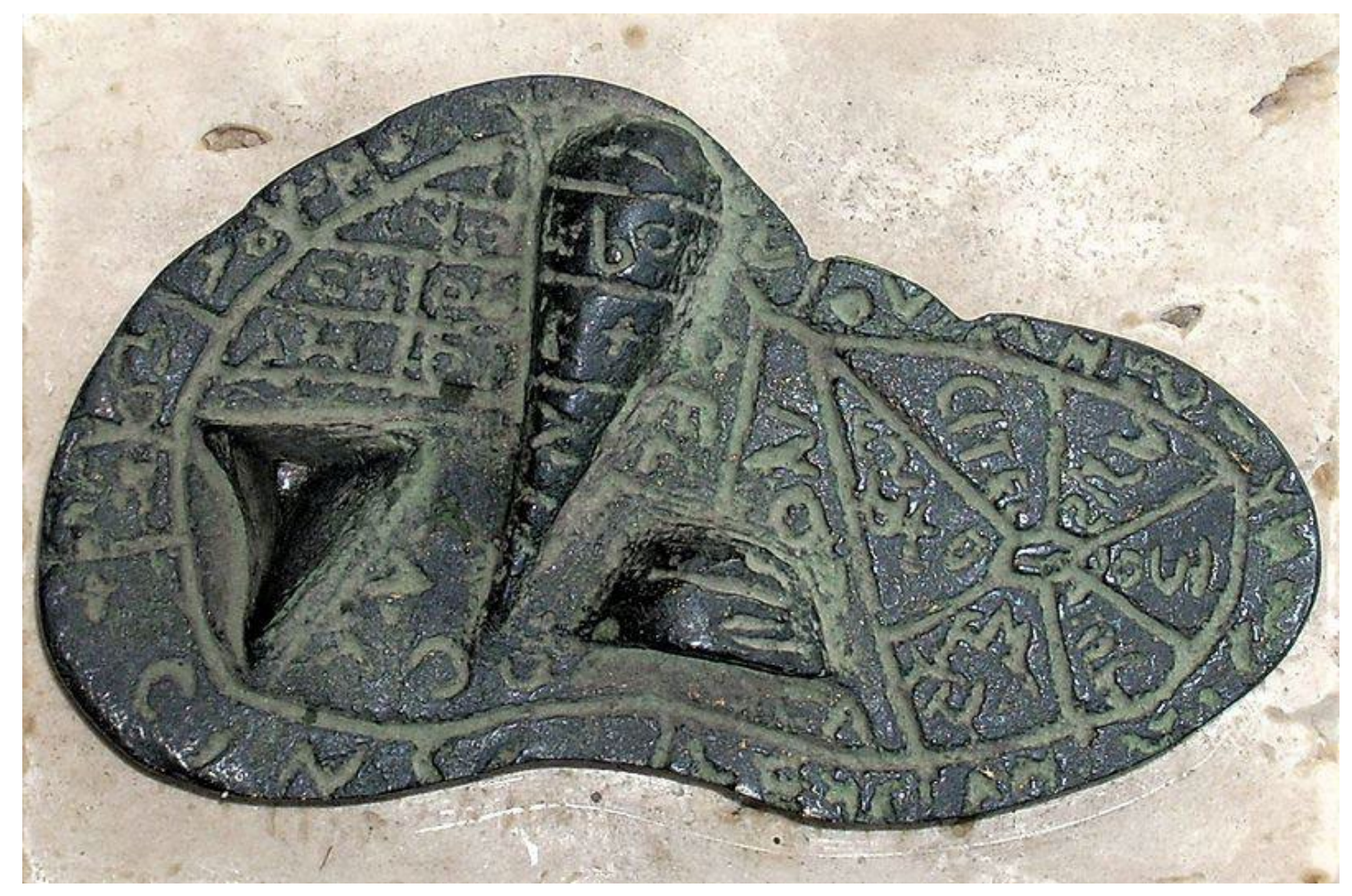

Artefato Etrusco. Fígado de Piacenza.

Séc. II e III.a.C.

Bronze

Piacenza: Museu Cívico (Palácio Farnese)

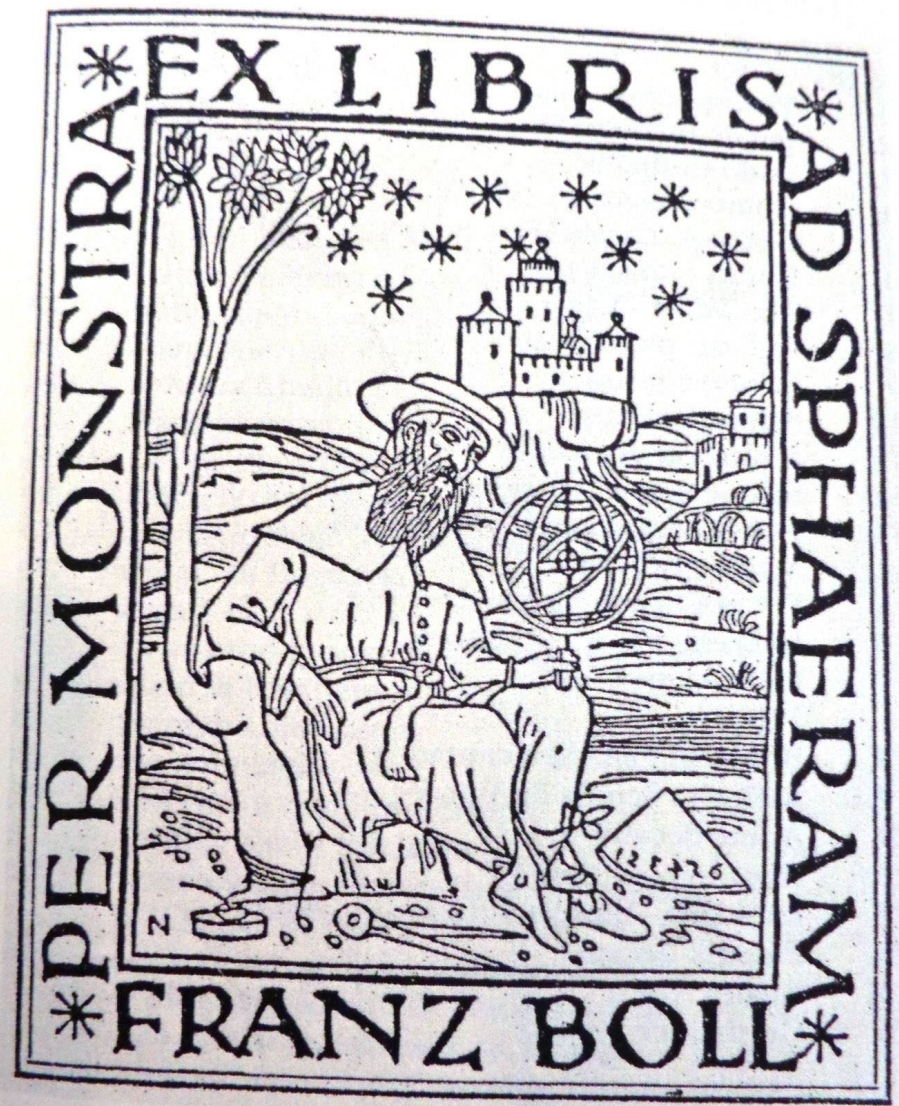

Edição do Astrolabiumplanum.

J. Engel(Augsburgo, 1488),

Com acréscimo do mote de Franz Boll, utilizado como ex-libris. 
Mas este problema, no que se refere ao estudo sobre a astrologia, será resolvido por Warburg apenas depois, nos apontamentos sobre Giordano Bruno, em 1928-1929. Na conferência de 1925, a problemática aparece apenas esboçada. Em 1925, ele cita Giordano Bruno (1548-1600) como aquele que concebeu a linguagem de um novo mundo. E afirma que, antes dele, Camillo Agrippa (1520-1595) teria intuído a ideia revolucionária do movimento da Terra em torno do Sol. O problema da descoberta do infinito estava, portanto, no centro dessa problemática.

Ainda na palestra de 1925, Warburg dedica-se a Kepler, que em Mysterium Kosmographicum (1569), concebe um sistema sólido de regulares encaixadas umas nas outras, designando a imagem simbólica das esferas. E cita a carta de Kepler, na qual argumenta a propósito da elipse:

Foi neste ponto [escreve Warburg] que o Prof. Cassirer me prestou ajuda, o qual me fez notar que, com efeito, Kepler, em sua correspondência de 1608 com Fabricius, argumentara energicamente contra este último que a elipse é por si mesma uma ideia matemática não subordinada, em termos de perfeição, ao círculo. Assim, graças à entrada da elipse, tornou-se possível deduzir a infinitude do universo em conformidade com a regularidade física. ${ }^{31}$

Tinha sido, então, Cassirer quem o ajudara compreender o papel de Kepler nesse processo. Cassirer, na carta a Warburg, de 12 de abril de 1924, transcreve algumas passagens da missiva de Kepler a Fabricius. Graças à ideia da elipse, em conformidade com a regularidade física, iniciava-se a explosão da esfera, que tinha norteado a relação entre homem e universo, entre indivíduo e cosmos, na concepção difundida no Alto Renascimento. Esta descoberta representava a crise do "homem vitruviano" de Leonardo da Vinci, da relação entre macro e microcosmo, da filosofia e, consequentemente, da astrologia do Renascimento. Era um passo adiante em relação à conquista da esfera.

Retomando de modo articulado a indicação de Cassirer, Warburg coloca Kepler na transição entre Renascimento e Mundo Moderno, entre astrologia e astronomia (embora esta separação não destruísse definitivamente o conhecimento astrológico, que, popularizado, existe ainda hoje). Warburg lançará luz sobre o fato de que Kepler, embora tenha também se rendido às práticas astrológicas mágicas, fora, no entanto, o primeiro a

${ }^{31}$ Ibem, p. 189. 
afirmar a importância da aritmética pura (ou seja, a utilização das operações de cálculo numérico) para o estudo do universo.

Franz Boll tinha intuído esse processo nas lições de verão ministradas em conjunto com Warburg em Hamburgo, em 1913, e que seriam sistematizadas pelo filólogo de Heidelberg em 1917, no livro Sternglaube und Sterndeutung. Die Geschichte und das Wesen der Astrologie (Interpretação e fé nos astros. História e caráter da astrologia). Assim afirmara Boll:

[...] o céu estrelado tornou-se menos vivo a partir de quando o telescópio descobriu milhões de corpos celestes e a ciência astronômica aprendeu a exprimir, em milhares de anos luz, distâncias inimagináveis. Tudo agora é distante, estranho e mudo. $^{32}$

A matemática apaga o céu. E faz também desaparecerem os quadros e afrescos astrológicos, que a partir de agora quase não serão mais pintados. A matemática substitui as imagens de tema astrológico. Para Warburg, na conferência de 1925:

Tratava-se de superar o temor primitivo [...]. Era exatamente contra a grosseira humanização exterior dos planetas, ocorrida através da identificação desses últimos com as divindades pagãs, que se tinha lançado, com um golpe certeiro e bemsucedido, Giordano Bruno. ${ }^{33}$

Nos apontamentos de 1928-1929, concebidos em 45 folhas de uma caderneta, Giordano Bruno representa, para Warburg, a abertura do caminho em direção à ideia abstrata do infinito. ${ }^{34}$ No Spaccio della Bestia Trionfante, Bruno teria expulso do céu, como "emblema dos vícios", as imagens clássicas de orientação. Warburg ia ao encontro dos estudos de Ernst Cassirer ${ }^{35}$, com quem manteve, nos últimos de sua vida, contato intelectual e de amizade. Cassirer chegara a Hamburgo em 1919, no momento da fundação da universidade local e ali permanecera até 1933. Cassirer dedicara a Warburg

\footnotetext{
${ }^{32}$ BOLL, F; BEZOLD, C. Interpretazione e fede negli astir. Storia e carattere dell'astrologia. (A cura di Maurizio Ghelardi) Livorno: Sillabe, 1999, p. 27.

33 WARBURG, A. A influência da Sphaera Barbarica sobre as tentativas de orientação no cosmos no Ocidente. Em memória de Franz Boll. In: WARBURG, A. A Presença do Antigo. Escritos inéditos. Vol. 1. Op. cit., p. 189.

${ }^{34}$ WARBURG, A. [Giordano Bruno]. In: WARBURG, A. Opere, II. La Rinascita del Paganesimo Antico e altri scritti (1917-1929). A cura di Maurizio Ghelardi. Torino: Nino Aragno Editore, 2008, pp. 921-993.

${ }^{35} \mathrm{O}$ recente volume apresenta os textos de Cassirer elaborados no período de sua atuação em Hamburgo, em contato com Aby Warburg e coma Biblioteca Warburg: CASSIRER, E. The Warburg Years (19191933). Essays on language, art, mith and technology. New Haven and London: Yale University Press, 2013.
} 
seus livros concebidos em 1926: Indivíduo e Cosmos na Filosofia do Renascimento ${ }^{36}$ e o primeiro dos volumes de $\boldsymbol{A}$ Filosofia das Formas Simbólicas ${ }^{37}$.

Em Indivíduo e Cosmos, o problema da relação entre sujeito e objeto na filosofia do Renascimento apresenta um teor facilmente reportável às conferências de Warburg sobre astrologia. Se tivermos presente, como um entre vários exemplos, a importância dada por Cassirer à matemática de Galileu, mas também à lógica e aos conceitos geométricos, como limitadores do pensamento medieval, não é difícil observar que estamos num terreno também habitado pelo pensamento dos últimos anos de Warburg. Se Cassirer compreende o papel da matemática na formulação de uma nova ciência da natureza, como elemento que reformula a relação entre indivíduo e cosmos na época de Galileu e de Giordano Bruno, Warburg concebe paralelamente o lugar do astrolábio como uma ferramenta mental a impor limites às imagens demonológicas tardo-medievais como forma de conhecimento astrológico. ${ }^{38}$ Para Warburg, era exatamente a matemática, somada à concepção filosófica do infinito, a portar uma nova organização do cosmos e a promover a possibilidade de vitória da razão sobre as fobias que preencheram de imagens demoníacas as representações astrológicas, ainda que os dois universos mentais pudessem conviver por longo tempo. Para Cassirer, a reformulação da relação entre indivíduo e cosmos, proposta pelas primeiras concepções da ciência moderna, atuava diretamente sobre uma nova consciência do homem em relação aos astros e, consequentemente, a respeito do poder que exercem sobre a vida prática. Isso representava, também para Cassirer, uma vitória da experiência sobre a superstição, da medição e do cálculo sobre a especulação, estabelecendo uma nova lógica para o conceito de natureza. Esta concepção coincide com a pesquisa de Warburg sobre o processo de superação da visão de mundo marcada pela astrologia medieval.

No Capítulo 4 de Indivíduo e Cosmos, intitulado "A problemática sujeito-objeto na filosofia do Renascimento", Cassirer defende que foi somente com Descartes, ou mesmo

\footnotetext{
${ }^{36}$ Edição brasileira: CASSIRER, E. Indivíduo e cosmo na filosofia do Renascimento. São Paulo: Martins Fontes, 2001. Edição original: Individuum und Kosmos in der Philosophie der Renaissance. Leipzig: Teubner, 1927.

${ }^{37}$ CASSIRER, E. Philosophie der symbolischen Formen. Op. cit.

${ }^{38}$ Maurizio Ghelardi trata esta problemática no Prefácio a mais recente edição italiana de Indivíduo e Cosmos de Cassirer. Ver: GHELARDI, M. Che cosa significa orientarsi nel pensiero. In: CASSIRER, E. Individuo e cosmo nella filosofia del Rinascimento. Torino: Bollati Boringhieri Editore, 2012, pp. IXXXXVII.
} 
(num certo sentido) com Leibniz, que se chega à formulação consciente sobre um ato livre do pensamento, que, de um só golpe, por uma decisão única e autônoma da vontade, trilha o novo caminho da reflexão consciente de si mesmo. Cassirer, no entanto, sem eliminar a compreensão desse processo como uma "revolução" no pensamento ocidental, busca as raízes dessa conquista intelectual. Raízes, segundo ele, constituídas por forças desprovidas de unidade, que, na maioria das vezes, lutam em oposição umas às outras, sem organização rigorosa. No entanto, todas essas forças empenham-se em revolver a relação entre sujeito e objeto.

Nessa tarefa engajam-se não apenas a metafísica, mas também a filosofia da natureza e o conhecimento empírico da natureza; não apenas a psicologia, mas também a ética e a estética. É nesse contexto que Cassirer interpreta a obra de Giordano Bruno.

Para o filósofo neo-kantiano, o que interessa a Bruno é a noção de cosmos infinito, embora não chegue a vislumbrar uma estrutura lógica do novo conceito matemático de infinito. ${ }^{39}$ Diferentemente de Kepler e de Galileu, não é a forma de uma nova ciência da dinâmica que captura o seu interesse. Mas a ideia de que a imaginação e o pensamento não devem ser detidos por quaisquer limites rígidos, seja dos espaços, seja das coisas. Para Bruno, o infinito não é matemático, não provém do cálculo, mas advém de um novo sentimento do mundo. O homem percebe o infinito com o mesmo instrumento com o qual percebe o seu "ser espiritual", a sua essência. O infinito, então, é um ato livre de elevação do espírito. A percepção do infinito é descrita, assim, como um ato do "eu". Portanto, há uma primazia da alma diante das demais coisas, de modo que o "eu" está à altura do "cosmos", pois encontra em si mesmo os princípios a partir dos quais pode conhecê-lo em sua infinitude. Há, assim, uma certeza intuitiva, que não provém do entendimento lógico, mas do princípio vital e específico do "eu". Agora, o infinito está dentro, no ser, e se projeta no espaço, também infinito, do cosmos. ${ }^{40}$

\footnotetext{
${ }^{39}$ Sobre este problema, ver também: GHELARDI, M. Aby Warburg: La lotta per lo stile. Torino: Nino Aragno Editore, 2012, pp. 241-271.

${ }^{40}$ Bruno trata esta problemática em: BRUNO, G. Acerca do Infinito, do Universo e dos Mundos. $6^{\mathrm{a}}$ edição. Lisboa: Fundação Calouste Gulbenkian, 2011, p. 28.

Ver a esse respeito: GHELARDI, M. Aby Warburg: La lotta per lo stile, op. cit., pp. 241-271.

Ver também, sobre este tema na obra de Giordano Bruno: CILIBERTO, M. Giordano Bruno. Bari: Laterza, 2018.
} 
É certo que Indivíduo e Cosmos de Cassirer causou em Warburg certo impacto e exerceu influência em suas anotações sobre Giordano Bruno, compostas em 1928-1929. Apesar do sentido fragmentário desses apontamentos, pode-se perceber a centralidade dada por Warburg aos livros de Bruno, Spaccio della bestia trionfante e Dialoghi italiani. Warburg vislumbra, na obra do filósofo de Nola, o entendimento lógico como forma de moderação e de autocontrole a combater as paixões desenfreadas provocadas pela compreensão relacional entre homem e cosmos na alma do homem tardo-medieval. Giordano Bruno, para Warburg, desempenha, então, o papel da deusa grega Sophrósyne, que assumia a ideia da sanidade moral e da prudência, para opor-se às paixões desenfreadas encarnadas na imagem da deusa Afrodite. A separação ideal entre indivíduo e cosmos, representada pela obra de Bruno, continha, para Warburg, um passo importante na nova posição ocupada pelo “eu”, agora assumindo a tarefa de observador e de parâmetro para o entendimento do movimento celeste. Este distanciamento anunciava, assim, uma nova posição do homem em relação ao cosmos e, consequentemente, uma renovada forma de orientar-se no pensamento.

Ao mesmo tempo, o diálogo intelectual que Warburg estabelece com Cassirer, fundamental para as conclusões a que chega em seus últimos anos, tornara-se significativo antes disso, e envolvia o tema da astrologia. Em 1924, ainda como paciente da clínica psiquiátrica na Suíça, Warburg escreve em seu caderno de apontamentos:

Certamente, gostaria de saber de Cassirer - e ele de mim - em que medida nós dois e Boll poderemos nos unir numa esfera mais alta, onde surge a modalidade da expressão humana que se orienta espiritualmente a partir da experiência de sua totalidade cósmica. ${ }^{41}$

Este trecho revela que Aby Warburg já aqui integrava Ernst Cassirer em seu intercâmbio intelectual com Franz Boll ${ }^{42}$, além de deixar entrever aquele que talvez fosse o problema central da pesquisa da fase final de sua vida, qual seja, o tema dos modos de orientação espiritual do homem no cosmos.

\footnotetext{
${ }^{41}$ WARBURG, Aby. Le potenze del destino riflesse nella simbolica anticheggiante. Riflessioni sulla funzione antitetica dell'Antico nella trasformazione energetica della personalità europea nell'epoca rinascimentale. In: WARBURG, A. Opere. II. La Rinascita del Paganesimo Antico e altri scritti (19171929). A cura di Maurizio Ghelardi. Torino: Nino Aragno Editore, 2007, pp. 217-218.

${ }^{42}$ Durante o contato com Warburg, Boll continuou trabalhando sobre o tema da astrologia, como fica atestado no citado volume: BOLL, Franz; BEZOLD, Carl. Interpretazione e fede negli astri, op. cit.
} 


\section{REFERÊNCIAS BIBLIOGRÁFICAS:}

ARATO. Fenómenos. Madrid: Editorial Gredos, 1993.

BOLL, Franz. Sphaera. Neue griechische Texte und Untersuchungen zur Geschichte der Sternbilder. Leipzig: Teubner, 1903.

BOLL, Franz; BEZOLD, Carl. Interpretazione e fede negli astir. Storia e carattere dell'astrologia. (A cura di Maurizio Ghelardi) Livorno: Sillabe, 1999.

BRUNO, Giordano. Acerca do Infinito, do Universo e dos Mundos. $6^{\text {a }}$ edição. Lisboa: Fundação Calouste Gulbenkian, 2011.

BURCKHARDT, Jacob. Jacob Burckhardt Werke. Band 6. München; Basel: C. H. Beck; Schwabe \& Co., 2000.

BURCKHARDT, Jacob. O Retrato na Pintura Italiana do Renascimento. (Organização, tradução e notas: Cássio Fernandes). Campinas; São Paulo: Editora da UNICAMP; Editora FAP-UNIFESP, 2012.

CASSIRER, Ernst. A Filosofia das Formas Simbólicas. 3 Volumes (A Linguagem; 2. O Pensamento Mítico; 3. Fenomenologia do Conhecimento). São Paulo: Martins Fontes, 2001-2011.

CASSIRER, Ernst. Indivíduo e cosmo na filosofia do Renascimento. São Paulo: Martins Fontes, 2001.

CASSIRER, Ernst. Individuum und Kosmos in der Philosophie der Renaissance. Leipzig: Teubner, 1927.

CASSIRER, Ernst. Philosophie der symbolischen Formen. 3 Bände (Band. 1. Der Sprache. Band. 2. Das mythische Denken. Band. 3. Phänomenologie der Erkenntnis.), Berlin: Bruno Cassirer Verlag, 1923-1929.

CASSIRER, Ernst. The Warburg Years (1919-1933). Essays on language, art, mith and technology. New Haven and London: Yale University Press, 2013.

CILIBERTO, Michele. Giordano Bruno. Bari: Laterza, 2018.

FRATUCELLO, Cinzia; KNORR, Christina (a cura di). Il Cosmo incantato di Schifanoia. Aby Warburg e la storia delle immagini astrologiche. Guida alla mostra. Palazzo Schifanoia - Ferrara, 1998.

GARIN, Eugenio. O Zodíaco da Vida. A polêmica sobre a astrologia do século XIV ao século XVI. Lisboa: Editorial Estampa, 1987.

GHELARDI, Maurizio. Aby Warburg: La lotta per lo stile. Torino: Nino Aragno Editore, 2012.

GHELARDI, Maurizio. Che cosa significa orientarsi nel pensiero. In: CASSIRER, Ernst. Individuo e cosmo nella filosofia del Rinascimento. Torino: Bollati Boringhieri Editore, 2012.

MA'SHAR, Abu. Introductorium in astronomiam Albumasaris Abalachi octo continens libros partiales. Venezia: Jacob Pentius Leucensis, 1506. 
SAXL, Fritz. La fede negli astri. Dell'antichità al Rinascimento. A cura di Salvatori Settis. Torino: Editore Boringhieri, 1985.

WARBURG, Aby. A Presença do Antigo. Escritos inéditos. Vol. 1. (Organização, tradução e notas: Cássio Fernandes). Campinas; São Paulo: Editora da UNICAMP; Editora da UNIFESP, 2018

WARBURG, Aby. A renovação da Antiguidade pagã. Rio de Janeiro: Editora Contraponto, 2013.

WARBURG, Aby. Gesammelte Schriften. Die Erneuerung der Heidnischen Antike. 2 Bande. Leipzig; Berlin: Teubner, 1932.

WARBURG, Aby. Heidnisch-antike Weissagung in Wort und Bild zu Luthers Zeiten. In: Sitzungsberichte der Heidelberger Akademie der Wissenschaften. Philologischhistorische Klasse, XXVI (1919), Heidelberg, 1920.

WARBURG, A. Historias de fantasmas para gente grande. Escritos, esboços e conferencias. Organizado por Leopoldo Waizbort. São Paulo, Companhia das Letras, 2015.

WARBURG, A. Opere. II. La Rinascita del Paganesimo Antico e altri scritti (19171929). A cura di Maurizio Ghelardi. Torino: Nino Aragno Editore, 2008.

WARBURG, Aby. Werke. Berlim: Suhrkamp Verlag, 2018. 